\title{
Anger Associated with Insomnia and Recent Stressful Life Events in Community-Dwelling Adults
}

\author{
Jichul Kim, Chang Woo Lee, Sehyun Jeon, Bum Joon Seok, and Seog Ju Kim \\ Department of Psychiatry, Sungkyunkwan University School of Medicine, Samsung Medical Center, Seoul, Korea
}

\begin{abstract}
Objective: The current study explored the influences of the association between insomnia and stressful events on the state or trait anger in community-dwelling adults. Methods: In total, 175 community-dwelling adults (101 females and 74 males, mean age, $41.30 \pm 8.45$ years) were recruited. All participants completed a self-reported questionnaire to assess insomnia and the Korean version of the State-Trait Anger Expression Inventory. Stressful life events during the last 6 months were also assessed in face to face interviews. Participants were divided into four groups based on the presence or absence of insomnia or recent stressful life events. Results: State anger (S-Anger), trait anger (TAnger), anger temperament (T-Anger/T), and anger reaction (T-Anger/R) differed significantly among the four groups according to insomnia and stressful events. Among normal sleepers, those with stressors showed higher T-Anger and T-Anger/R scores than those without stressors. Among those who experienced stressful life events, the S-Anger scores were higher in those with than in those without insomnia. Subjects who experienced insomnia after stressful events exhibited higher scores in all anger categories compared to normal sleepers without stressful events. Conclusion: The present study provides support for an association between sleep reactivity after stressors and the anger. Stress-related insomnia is associated with state and trait anger in community-dwelling adults.
\end{abstract}

Key Words: State anger; Trait Anger; Anger temperament; Anger reaction; Insomnia; Stress

Received: November 18, 2019 Revised: December 11, 2019 Accepted: December 11, 2019

Corresponding author: Seog Ju Kim, MD, PhD, Department of Psychiatry, Sungkyunkwan University School of Medicine, Samsung Medical Center, 81 Irwon-ro, Gangnam-gu, Seoul 06351, Korea.

Tel: 82-2-3410-3583, Fax: 82-2-3410-0050, E-mail: ksj7126@skku.edu

(a) This is an Open Access article distributed under the terms of the Creative Commons Attribution Non-Commercial License (https://creativecommons.org/licenses/by$\mathrm{nc} / 4.0)$ which permits unrestricted non-commercial use, distribution, and reproduction in any medium, provided the original work is properly cited.

\section{INTRODUCTION}

Insomnia is affected by various predisposing factors, precipitating factors, and their interactions [1]. Among them, hyperarousal and stress dysregulation have been suggested as the main causes of insomnia. According to this theoretical model, both sleep reactivity, as a predisposing factor, and the stressful events, as a precipitating factor, are important to the development of insomnia.

Exposure to stressors activates the sympathetic nervous system and the hypothalamic-pituitary-adrenal, which increases adrenaline levels and disturbs sleep [2,3]. However, there are large individual differences in the amount of sleep disturbance experienced, even in response to the similar stressful events. To explain these inter-individual differences, studies have suggested the concept of sleep reactivity, a trait defined by the degree to which stressors disrupt sleep. A number of factors, such as ge- netic background, gender, environmental stress, and cognitiveemotional reactivity, have been reported to influence sleep reactivity $[1,4,5]$.

A growing body of research indicates that sleep and emotions are closely linked. The relationship between sleep and emotions is bidirectional [6]. That is, poor sleep may lead to emotional dysfunction, and negative emotions may lead to sleep disturbance. Our previous study also reported that insomnia and recent stressful life events have interactive effects on depression and anxiety [7].

In particular, the emotional state of anger may be salient to sleep in that it can trigger arousal [6]. Anger is reportedly correlated with increased somatic tension before sleep, difficulty initiating sleep, and poor quality of sleep [8]. The predisposition towards anger also predicts various sleep disturbances, including difficulty falling or staying asleep, early-morning awakening, and excessive daytime sleepiness [9]. In addition, sleep-deprived sub- 
jects have been reported to exhibit more intense negative moods, such as anger, compared to those with adequate sleep [10].

It is likely that sleep reactivity is associated with anger because insomnia and anger are closely associated with stress. However, relatively little attention has been paid to the interrelations among insomnia, stress, and anger experience. In the current study, we compared anger among different groups divided according to the presence and absence of insomnia symptoms and negative stressors. We hypothesized that state or trait anger would be higher in people with insomnia who were experiencing a recent stressful event than in those without insomnia or without recent stressors.

\section{METHODS}

\section{Participants}

Community-dwelling adults were recruited by advertisements in four different sites (apartment buildings, a church, a public health center, and a university) located in Incheon, South Korea. In total, 175 subjects [mean age, $41.30 \pm 8.45$ years (range, 20-65 years); 101 females and 74 males] submitted the written informed consent form prior to participation. All participants completed the interview and self-reported questionnaires. The Institutional Review Boards of Gachon University of Medicine and Science approved this study protocol.

\section{Assessment of insomnia}

Insomnia was assessed by a four-item self-report based on the criteria of International Classification of Sleep Disorders which asked about the following experiences: 1) difficulty initiating sleep, 2) difficulty maintaining sleep, 3) waking early with difficulty getting back to sleep, and 4) distress or impaired functioning during daytime [11].

Clinical insomnia was defined if any type of insomnia symptoms (i.e., initial, maintenance or terminal) occurred more than 3 nights per week and if participants experienced daytime functional impairment due to insomnia. The current study also defined subclinical insomnia as the mild form of sleep disturbance that did not meet the diagnostic criteria for clinical insomnia. Subclinical insomnia was defined as any type of insomnia at least one night per week, with complaints of subjective distress [7].

\section{Assessment of stressors}

All participants were interviewed concerning negative life events within the past 6 months to investigate the effects of recent stress on sleep. The interview questions included six situations used in previous studies: 1) the death of a family member or close friend; 2) serious illness in one's self or a family member; 3) serious economic crisis; 4) unwanted retirement or dismissal from work; 5) severe interpersonal conflicts with family, friends, relatives, or colleagues; 6) divorce or unwanted breakdown of an interpersonal relationship [12].

\section{Assessment of anger}

Anger was measured by using the validated Korean version of the State-Trait Anger Expression Inventory (STAXI) [13]. The STAXI was developed to evaluate the experience and expression of anger [14]. In this study, we were interested in the intensity of anger as an emotional state and anger proneness as a personality trait. Thus, only 20 items were included to measure state and trait anger. State anger (S-Anger) is defined as an emotional state including angry feelings. Trait anger (T-Anger) refers to a predisposition towards anger. Trait anger comprised two subscales: angry temperament (T-Anger/T) and angry reaction (T-Anger/R). Angry temperament describes a general tendency to experience anger without any provoking circumstance. Angry reaction refers to the disposition to become angry in response to provoking situations, such as frustration and negative evaluations [13].

\section{Statistical analysis}

All data were analyzed using SPSS version 22 software (IBM Corp., Armonk, NY, USA). The nonparametric Kruskal-Wallis test was performed to compare the continuous variables across groups, as most data were not normally distributed. Post hoc analysis was performed using a nonparametric Mann-Whitney U-test. A p-value $<0.05$ was considered significant.

\section{RESULTS}

\section{Clinical insomnia, stressors, and anger}

All participants were classified into four groups according to clinical insomnia and recent stress status: 1$)$ normal sleep without stress $(n=123 ; 54$ males and 69 females; mean age, $41.10 \pm 8.62$ years); 2 ) normal sleep with stress ( $n=31 ; 9$ males and 22 females; mean age, $41.90 \pm 6.81$ years); 3) clinical insomnia without stress $(\mathrm{n}=9 ; 5$ males and 4 females; mean age, $41.33 \pm 12.25$ years); and 4) clinical insomnia with stress ( $n=12 ; 6$ males and 6 females; mean age, $41.83 \pm 8.21$ years). No difference in age was observed $(\mathrm{p}=0.908)$.

The S-Anger, T-Anger, T-Anger/T, and T-Anger/R scores were significantly different among groups (Table 1). The S-Anger scores were higher in participants with clinical insomnia and stress than in normal sleepers without stress $(\mathrm{p}=0.001)$ and normal sleepers with stress $(\mathrm{p}=0.002)$. The T-Anger scores were higher in those with clinical insomnia and stress than in the three other groups (vs. normal sleepers without stress, $\mathrm{p}=0.034$; vs. normal sleepers with stress, $\mathrm{p}=0.007$; vs. clinical insomnia without stress, $\mathrm{p}=0.035)$. Normal sleepers with stress had higher T-Anger scores than did normal sleepers without stress $(\mathrm{p}=0.034)$. T-Anger/T scores were higher in those with clinical insomnia and stress than in normal sleepers without stress $(\mathrm{p}=0.026)$. Clinical insomnia with stress had higher T-Anger/R scores than did normal sleepers without stress $(p=0.002)$. Normal sleepers with stress had higher T-Anger/R than did normal sleepers without stress $(\mathrm{p}=0.010)$. 
Table 1. Anger levels according to clinical insomnia and stress status

\begin{tabular}{|c|c|c|c|c|c|c|c|}
\hline & $\begin{array}{c}\text { Normal sleep } \\
\text { without stress }(\mathrm{N}) \\
\quad(\mathrm{n}=123)\end{array}$ & $\begin{array}{l}\text { Normal sleep } \\
\text { with stress (NS) } \\
\quad(\mathrm{n}=31)\end{array}$ & $\begin{array}{l}\text { Insomnia without } \\
\text { stress (I) } \\
(\mathrm{n}=9)\end{array}$ & $\begin{array}{l}\text { Insomnia with } \\
\text { stress (IS) } \\
(\mathrm{n}=12)\end{array}$ & $\begin{array}{l}\text { Statistic } \\
\text { (Kruskal- } \\
\left.\text { Wallis } \chi^{2}\right)\end{array}$ & $\mathrm{p}$-value & Post hoc analysis \\
\hline Age (yr) & $41.10 \pm 8.62$ & $41.90 \pm 6.81$ & $41.33 \pm 12.25$ & $41.83 \pm 8.21$ & & $0.908^{\S}$ & \\
\hline Sex, n & & & & & & $0.347^{\ddagger}$ & \\
\hline Male & 54 & 9 & 5 & 6 & & & \\
\hline Female & 69 & 22 & 4 & 6 & & & \\
\hline \multicolumn{8}{|l|}{ Anger (STAXI) } \\
\hline S-Anger & $12.47 \pm 3.97$ & $12.35 \pm 4.14$ & $13.00 \pm 3.46$ & $18.58 \pm 7.43$ & 11.68 & $0.009 \S$ & $\mathrm{N}<\mathrm{IS}^{\dagger}, \mathrm{NS}<\mathrm{IS}^{\dagger}$ \\
\hline T-Anger & $19.90 \pm 4.39$ & $21.90 \pm 4.38$ & $21.89 \pm 5.30$ & $26.25 \pm 7.20$ & 7.72 & $0.004 \S$ & $\mathrm{N}<\mathrm{NS}^{*}, \mathrm{~N}<\mathrm{IS}^{\dagger}$ \\
\hline T-Anger/T & $7.60 \pm 2.44$ & $8.10 \pm 2.07$ & $9.11 \pm 2.32$ & $9.58 \pm 3.34$ & 8.24 & $0.041^{\S}$ & $\mathrm{N}<\mathrm{IS}^{*}$ \\
\hline T-Anger/R & $9.23 \pm 2.29$ & $10.58 \pm 2.68$ & $9.67 \pm 3.35$ & $11.17 \pm 1.70$ & 13.75 & $0.003 \S$ & $\mathrm{N}<\mathrm{NS}^{*}, \mathrm{~N}<\mathrm{IS}^{\dagger}$ \\
\hline
\end{tabular}

Data are presented as mean \pm SD unless otherwise noticed. Kruskal-Wallis test was used to compare distribution of ranks across the four groups. For post hoc comparison, Mann-Whitney U-test was used. ${ }^{*} \mathrm{p}<0.05,{ }^{\dagger} \mathrm{p}<0.01$, ${ }^{\ddagger}$ chi-square test, ${ }^{\S}$ Kruskal-Wallis test. STAXI: State-Trait Anger Expression Inventory, S-Anger: STAXI, state anxiety, T-Anger: STAXI, trait anxiety, T-Anger/T: STAXI, a subscale of trait anger, anger temperament, T-Anger/R: STAXI, a subscale of trait anger, anger reaction

Table 2. Anger levels according to subclinical insomnia and stress status

\begin{tabular}{|c|c|c|c|c|c|c|c|}
\hline & $\begin{array}{c}\text { Good sleep } \\
\text { without stress }(\mathrm{G}) \\
(\mathrm{n}=59)\end{array}$ & $\begin{array}{l}\text { Good sleep with } \\
\text { stress (GS) } \\
(\mathrm{n}=19)\end{array}$ & $\begin{array}{l}\text { Subclinical insomnial } \\
\text { without stress (I) } \\
(\mathrm{n}=73)\end{array}$ & $\begin{array}{l}\text { Subclinical insomnia" } \\
\text { with stress (IS) } \\
(\mathrm{n}=24)\end{array}$ & $\begin{array}{l}\text { Statistic } \\
\text { (Kruskal- } \\
\text { Wallis } \chi^{2} \text { ) }\end{array}$ & $\mathrm{p}$-value & Post hoc analysis \\
\hline Age (yr) & $40.39 \pm 8.15$ & $40.74 \pm 6.16$ & $41.70 \pm 9.40$ & $42.79 \pm 7.82$ & & $0.618^{\S}$ & \\
\hline Sex, n & & & & & & $0.390^{\ddagger}$ & \\
\hline Male & 24 & 5 & 35 & 10 & & & \\
\hline Female & 35 & 14 & 38 & 14 & & & \\
\hline \multicolumn{8}{|l|}{ Anger (STAXI) } \\
\hline S-Anger & $12.31 \pm 3.56$ & $12.00 \pm 2.19$ & $12.67 \pm 4.22$ & $15.75 \pm 7.29$ & 4.41 & $0.220^{\S}$ & \\
\hline T-Anger & $20.17 \pm 4.68$ & $22.21 \pm 3.57$ & $19.93 \pm 4.31$ & $23.83 \pm 6.76$ & 9.64 & $0.022 \S$ & $\mathrm{G}<\mathrm{IS}^{*}, \mathrm{I}<\mathrm{GS}^{*}, \mathrm{I}<\mathrm{IS} *$ \\
\hline T-Anger/T & $7.63 \pm 2.72$ & $8.37 \pm 1.83$ & $7.78 \pm 2.23$ & $8.63 \pm 3.02$ & 3.39 & $0.336^{\S}$ & \\
\hline T-Anger/R & $9.41 \pm 2.29$ & $10.42 \pm 2.48$ & $9.14 \pm 2.43$ & $11.00 \pm 2.43$ & 13.31 & $0.004 \S$ & $\mathrm{G}<\mathrm{IS}^{\dagger}, \mathrm{I}<\mathrm{GS}^{*}, \mathrm{I}<\mathrm{IS}^{\dagger}$ \\
\hline
\end{tabular}

Data are presented as mean \pm SD unless otherwise noticed. Kruskal-Wallis test was used to compare distribution of ranks across the four groups. For post hoc comparison, Mann-Whitney U-test was used. ${ }^{*} \mathrm{p}<0.05,{ }^{\dagger} \mathrm{p}<0.01$, ${ }^{\ddagger}$ chi-square test, §Kruskal-Wallis test, "subclinical insomnia was defined as insomnia at least one night per week with complaints of subjective distress. STAXI: State-Trait Anger Expression Inventory, S-Anger: STAXI, state anxiety, T-Anger: STAXI, trait anxiety, T-Anger/T: STAXI, a subscale of trait anger, anger temperament, T-Anger/R: STAXI, a subscale of trait anger, anger reaction

\section{Subclinical insomnia, stressors, and anger}

All participants were classified into four groups according to subclinical insomnia and recent stress status: 1) good sleepers without stress $(\mathrm{n}=59 ; 24$ males and 35 females; mean age, $40.39 \pm 8.15$ years); 2 ) good sleepers with stress ( $\mathrm{n}=19 ; 5$ males and 14 females; mean age, $40.74 \pm 6.16$ years); 3) subclinical insomnia without stress ( $\mathrm{n}=73,35$ males and 38 females; mean age, $41.70 \pm 9.40$ years); and 4 ) subclinical insomnia with stress ( $\mathrm{n}=24$, 10 males and 14 females; mean age, $42.79 \pm 7.82$ years). No significant difference in age was observed among the groups $(\mathrm{p}=0.618)$.

The T-Anger $(\mathrm{F}=9.64, \mathrm{p}=0.022)$ and the $\mathrm{T}$-Anger/ $\mathrm{R}(\mathrm{F}=13.31$, $\mathrm{p}=0.004$ ) scores were significantly different among groups (Table 2). The T-Anger scores were significantly higher in subclinical insomnia with stress than in good sleepers without stress $(\mathrm{p}=0.024)$ and subclinical insomnia without stress $(\mathrm{p}=0.015)$. Good sleepers with stress showed higher T-Anger scores than did those with subclinical insomnia and no stress $(\mathrm{p}=0.036)$. The T-Anger/R scores were significantly higher in those with subclinical insomnia and stress than in good sleepers without stress $(\mathrm{p}=0.004)$ and those with subclinical insomnia but no stress ( $\mathrm{p}=0.001$ ). The T-Anger/R scores were higher in the good sleepers with stress than those with subclinical insomnia and no stress $(\mathrm{p}=0.049)$.

\section{DISCUSSION}

The present study investigated the associations between the stress-related insomnia and anger experience in communitydwelling adults. We assessed anger in subjects with clinical/subclinical insomnia symptoms compared to normal sleepers in the presence or absence of a recent stressful event. In the current study, significant differences were detected in state and trait anger among the groups.

Only those who reported both insomnia and stressors showed higher state and trait anger than those who had neither insomnia nor stressors, suggesting that both insomnia and stressful life events may contribute to anger. In addition, among those without insomnia, those who had experienced stressful events showed 
higher trait anger, particularly reactive anger. This finding suggests that those with higher anger reactivity are prone to evaluate their life events more negatively.

In addition, clinical insomnia after stressful life events was more common among those with higher state anger than those without insomnia even after stressful experiences. Insomnia after stressful events may be an indicator of sleep reactivity. The impact of stressful experiences on sleep, that is, sleep reactivity, is influenced by coping strategies or personality [9,15-17]. The current study suggests that higher sleep reactivity is related to anger. In addition, this finding also suggests that sleep may attenuate the anger provoked by negative and stressful life events. Good sleep is proposed to play a role in emotional processing, while altered sleep may trigger emotional disturbances including anger $[17,18]$.

Insomnia after stressful life events was more related to trait anger, particularly reactive anger, than was insomnia unrelated to stressful events. Furthermore, those with insomnia unrelated to stressor exhibited lower trait anger than those without insomnia after stressful events. The current results suggest that insomnia may be a physiological indicator of a severe reaction to stressful experiences in a person with a predisposition towards anger. Individuals predisposed toward anger are more susceptible to insomnia symptoms caused by stress and may be unable to sleep in stressful situations. These results also suggest that insomnia related to stress is etiologically different from insomnia unrelated to stress. Insomnia without preceding stressors may be caused by other medical or environmental causes, such as sleep apnea or circadian misalignment.

However, differences in trait anger between stress-related insomnia and non-stress-related insomnia could be found only when the criteria for subclinical insomnia were applied. This discrepancy may be due to the characteristics of insomnia related to recent stressful events. Insomnia caused by anger toward a stressor may be milder. In the case of insomnia caused by reactive anger due to mild or temporary stress, the subsequent sleep difficulties may also be transient or intermittent. Otherwise, subclinical insomnia without stressors may be a non-specific variation in a sleep pattern that is generally unrelated to emotions.

This study has several limitations. First, insomnia symptoms and anger variables were measured solely by self-reported questionnaires and were obtained only once. With the cross-sectional design of our study, it was difficult to clarify the causal relationship between stressful life events, insomnia symptoms, and anger. Second, the sample size was small, particularly for certain groups. A future study with a large sample size is needed to establish the validity of our findings. Finally, we did not consider the degree of stressful events.

The current study showed that individuals in a communitydwelling population who have a predisposition to anger may have insomnia when confronting stressful events. An interactive effect of insomnia and stressful life events on feeling of anger was also noted. The current findings support the notion that sleep reactivity to a stressor is associated with trait or state anger.
Acknowledgments

None

\section{Conflicts of Interest}

The authors have no potential conflicts of interest to disclose.

\section{Author Contributions}

Conceptualization: Seog Ju Kim. Data curation: Seog Ju Kim, Sehyun Jeon, Jichul Kim. Formal analysis: Sehyun Jeon, Jichul Kim. Funding acquisition: Seog Ju Kim. Investigation: Seog Ju Kim, Jichul Kim. Methodology: Seog Ju Kim, Chang Woo Lee, Jichul Kim. Project administration: Seog Ju Kim. Resources: Seog Ju Kim. Supervision: Seog Ju Kim. Software: Sehyun Jeon, Chang Woo Lee. Validation: Sehyun Jeon, Bum Joon Seok. Visualization: Jichul Kim. Writing_original draft: Jichul Kim. Writingreview \& editing: Sehyun Jeon, Seog Ju Kim.

\section{ORCID iDs}

Seog Ju Kim (1)

https://orcid.org/0000-0003-2467-5451

Jichul Kim (1)

https://orcid.org/0000-0002-7660-4252

\section{REFERENCES}

1. Kalmbach DA, Cuamatzi-Castelan AS, Tonnu CV, Tran KM, Anderson JR, Roth T, et al. Hyperarousal and sleep reactivity in insomnia: current insights. Nat Sci Sleep 2018;10:193-201.

2. Hall M, Buysse DJ, Nowell PD, Nofzinger EA, Houck P, Reynolds CF 3rd, et al. Symptoms of stress and depression as correlates of sleep in primary insomnia. Psychosom Med 2000;62:227-230.

3. Kamphuis J, Meerlo P, Koolhaas JM, Lancel M. Poor sleep as a potential causal factor in aggression and violence. Sleep Med 2012;13:327-334.

4. Drake CL, Pillai V, Roth T. Stress and sleep reactivity: a prospective investigation of the stress-diathesis model of insomnia. Sleep 2014;37:1295-1304.

5. Fernández-Mendoza J, Vela-Bueno A, Vgontzas AN, Ramos-Platón MJ, Olavarrieta-Bernardino S, Bixler EO, et al. Cognitive-emotional hyperarousal as a premorbid characteristic of individuals vulnerable to insomnia. Psychosom Med 2010;72:397-403.

6. Kahn M, Sheppes G, Sadeh A. Sleep and emotions: bidirectional links and underlying mechanisms. Int J Psychophysiol 2013;89:218-228.

7. Lee CW, Jeon S, Kim J, Seok BJ, Kim SJ. Depression and anxiety associated with insomnia and recent stressful life events. Chronobiol Med 2019;1:121125 .

8. Waters WF, Adams SG Jr, Binks P, Varnado P. Attention, stress and negative emotion in persistent sleep-onset and sleep-maintenance insomnia. Sleep 1993;16:128-136

9. Shin C, Kim J, Yi H, Lee H, Lee J, Shin K. Relationship between trait-anger and sleep disturbances in middle-aged men and women. J Psychosom Res 2005;58:183-189.

10. Paterson JL, Dorrian J, Ferguson SA, Jay SM, Lamond N, Murphy PJ, et al. Changes in structural aspects of mood during 39-66 h of sleep loss using matched controls. Appl Ergon 2011;42:196-201.

11. American Academy of Sleep Medicine. International classification of sleep disorders: diagnostic and coding manual. 2nd ed. Westchester, IL: American Academy of Sleep Medicine, 2005

12. Kim SJ, Cho SJ, Jang HM, Shin J, Park PW, Lee YJ, et al. Interaction between brain-derived neurotrophic factor Val66Met polymorphism and recent negative stressor in harm avoidance. Neuropsychobiology 2010;61:19-26.

13. Chon KK, Hahn DW, Lee CH, Spielberger CD. Korean adaptation of the State-Trait Anger Expression Inventory: anger and blood pressure. Korean J Health Psychol 1997;2:60-78. 
14. Spielberger CD. State-Trait Anger Expression Inventory research edition. Professional manual. Odessa, FL: Psychological Assessment Resources, 1988.

15. Germain A, Buysse DJ, Ombao H, Kupfer DJ, Hall M. Psychophysiological reactivity and coping styles influence the effects of acute stress exposure on rapid eye movement sleep. Psychosom Med 2003;65:857-864.

16. Kashani M, Eliasson A, Vernalis M. Perceived stress correlates with dis- turbed sleep: a link connecting stress and cardiovascular disease. Stress 2012;15:45-51.

17. Deliens G, Gilson M, Peigneux P. Sleep and the processing of emotions. Exp Brain Res 2014;232:1403-1414.

18. Killgore WD, Kahn-Greene ET, Lipizzi EL, Newman RA, Kamimori GH, Balkin TJ. Sleep deprivation reduces perceived emotional intelligence and constructive thinking skills. Sleep Med 2008;9:517-526. 